\title{
ESPAÇOS ABERTOS EM INSTITUIÇÕES PARA IDOSOS
}

\author{
Sérgio Luiz V. Tomasini ${ }^{1}$ \\ Beatriz Fedrizzi ${ }^{2}$
}

\section{Resumo}

O presente artigo apresenta uma série de discussões acerca da importância da presença de espaços abertos junto a instituições para idosos, tomando por base os resultados de uma pesquisa de mestrado centrada neste tema e desenvolvida a partir do estudo da realidade vigente no município de Porto Alegre-RS. A referida pesquisa foi desenvolvida basicamente a partir de dois estudos de campo: o primeiro, um levantamento preliminar em que foram analisadas características físicas dos espaços abertos de uma amostra de 12 instituições; e o segundo, um estudo de casos comparativo envolvendo duas instituições com diferentes condições de disponibilidade e qualidade de espaços abertos. Os resultados do primeiro estudo demonstraram um panorama predominantemente negativo quanto à presença e qualidade dos espaços abertos disponíveis nas instituições, com espaços demasiadamente restritos, pouco funcionais e esteticamente pouco interessantes. O segundo estudo, por outro lado, demonstrou, entre outros resultados não abordados neste artigo, uma influência da qualidade do pátio sobre a satisfação dos idosos em relação à instituição e sobre o tempo de permanência dos mesmos nas áreas externas. Este estudo revelou ainda que, de forma geral, os idosos utilizam muito pouco outros espaços abertos fora da instituição, como parques e praças, o que reforça a importância da presença de locais desta natureza junto à instituição.

Palavras-chave: Instituições para Idosos. Espaços Abertos. Qualidade de Vida.

\footnotetext{
${ }^{1}$ Eng. Agr. Msc, Doutorando pelo Programa de Pós-Graduação em Engenharia Civil - UFRGS E-mail: sergiovtomasini@yahoo.com.br

${ }^{2}$ Eng. Agr. PhD, Professora do Programa de Pós-Graduação em Engenharia Civil - UFRGS

E-mail: beatrizfedrizzi@yahoo.com.br
} 


\section{Introdução}

Atualmente bastante divulgado pela mídia, o envelhecimento da população brasileira tem sido uma das principais causas do crescente interesse da sociedade acerca da qualidade de vida dos indivíduos que atingem a terceira idade. Em decorrência dessa preocupação, muito se tem avançado na discussão e apresentação de alternativas, nas mais diversas áreas de conhecimento aplicado, que visam tornar o envelhecimento uma experiência não somente menos penosa, mas também uma etapa de crescimento e realizações pessoais.

Dentre os muitos aspectos discutidos em relação aos impactos do envelhecimento populacional e à busca de alternativas para lidar com esse fenômeno, destaca-se aqui a questão relacionada à moradia. Embora a maior parte das discussões relacionadas à habitação para os idosos aponte a permanência no lar, junto à família, como a alternativa mais viável sob muitos aspectos, as instituições para idosos ainda se apresentam como uma realidade bastante presente no Brasil. Estas instituições constituem, muitas vezes, a única alternativa de moradia para muitas pessoas, especialmente para aquelas que compõem a parcela mais carente e/ou debilitada da população de idosos.

Preocupado com a qualidade de vida vigente em instituições para idosos, particularmente sob o ponto de vista das instalações físicas oferecidas aos residentes, este artigo procura discutir a importância da presença e da qualidade dos espaços abertos (áreas externas ou pátios) junto a essas instituições. Os espaços abertos, quando convenientemente tratados, podem conjugar uma série de características importantes para a sensação de bemestar e mesmo para a saúde dos idosos. Além dos efeitos diretos que os espaços abertos podem exercer sobre a saúde dos idosos, ao proporcionar locais onde eles possam tomar sol, respirar ar fresco e se exercitar, outros importantes benefícios podem ser mencionados.

Para Stoneham; Thoday (1994), espaços abertos bem projetados ${ }^{3}$ podem contribuir para uma melhor qualidade de vida dos idosos ao aumen-

\footnotetext{
3 Entende-se aqui por espaços abertos bem projetados aqueles planejados com base no estudo das necessidades dos usuários para os quais se destinam. O conceito de planejamento com base nas necessidades dos usuários tem sido amplamente difundido na área da construção civil pela abordagem de Desempenho de Edificações. Basicamente, esta abordagem implica em dizer que a função ou fim de um determinado produto é satisfazer as exigências ou necessidades de seus usuários (CONSEIL INTERNATIONAL DU BÂTIMENT, 1982).
} 
tar as oportunidades de atividades e interesses, ampliando os horizontes sociais e reduzindo sentimentos de isolamento para com o mundo exterior. Sentar-se em um banco ao ar livre ou caminhar através dos espaços externos pode proporcionar o contato com plantas e uma oportunidade para coletar materiais para hobbies, como o preparo de arranjos de flores ou o preparo de alimentos. O jardim pode também ser importante ao proporcionar locais adicionais de privacidade em relação à casa. Isto define um território pessoal e proporciona interesse e motivos para aguardar com satisfação o passar do tempo. Por outro lado, um design pobre dos espaços abertos pode agravar e intensificar problemas de isolamento, solidão, perda de capacidades e redução da imagem pessoal.

Atividades que envolvem o contato com as plantas e com o solo são possibilidades oferecidas pelo acesso a espaços abertos que parecem exercer um efeito terapêutico sobre as pessoas. Kaplan ${ }^{4}$ (1973 apud FEDRIZZI), demonstrou através de suas pesquisas que as atividades de jardinagem e horticultura produzem uma grande satisfação e tranqüilidade no ser humano. Observaram, ainda, que o ser humano demonstra grande prazer em cultivar seu próprio alimento, em dividir a colheita com outras pessoas, em trocar informações sobre o assunto e observar o crescimento das plantas. A grande satisfação dessas atividades estaria ligada ao solo, ao verde, às flores e hortaliças, às árvores e ao local. Identificaram, também, que pessoas que perdem o controle das suas vidas, quando se dedicam a essas atividades, de alguma forma, em maior ou menor grau, recuperam o controle.

Um estudo realizado por Küller et al. (1990) demonstrou claramente relações positivas de indivíduos da terceira idade com os espaços abertos. Estudando idosos residentes na Suécia e na Turquia, estes pesquisadores constataram que os idosos de ambos países que dedicavam mais horas de suas vidas a atividades ao ar livre, ou simplesmente a "tomar sol", expondose diretamente à luz do dia, tinham melhor qualidade de vida. Estes necessitavam ir menos vezes ao médico, apresentavam melhor saúde, melhores níveis hormonais e melhor qualidade de sono. Os indivíduos pesquisados que passavam mais horas do dia expostos ao ar livre e luz natural ainda se mantinham mais alertas, mais tranquiilos, com melhor senso de orientação e com menor ocorrência de estados de depressão.

\footnotetext{
${ }^{4}$ KAPLAN, R. Some Psychological Benefits of Gardening. Environment and Behavior, Beverly
} Hills, v. 5, n. 2, p. 145-161, 1973. Apud FEDRIZZI, 1998. P. 34. 
Pode-se citar ainda os benefícios que os espaços abertos podem trazer ao estabelecer interações positivas com as edificações disponíveis no ambiente das instituições. Estas interações refletem-se, em última análise, na sensação de conforto dentro das edificações e estão relacionadas, principalmente, com os benefícios térmicos da presença de vegetação nestes locais. Neste sentido, a cuidadosa disposição da vegetação no entorno de edificações tem sido reconhecida há muito tempo como uma forma de melhorar as condições térmicas das habitações. A vegetação influencia o ganho de calor pelas edificações através de processos que envolvem a interceptação dos raios solares (sombreamento), proteção contra infiltrações de ar e a criação de microclimas resfriados ao redor das edificações (CANTUARIA, 1995).

Tendo em vista a importância da presença de espaços abertos junto a instituições para idosos, deduz-se que o planejamento adequado dos mesmos seja fundamental no sentido de garantir que seus benefícios efetivamente se façam sentir sobre seus usuários. Infelizmente, o que se pode observar é que o planejamento destes espaços ainda é um tema pouco explorado, mesmo entre os países desenvolvidos. Referindo-se à experiência destes países, Stoneham; Thoday (1994) afirmam que, recentemente, consideráveis avanços têm sido verificados em relação ao design de edificações em função das necessidades particulares de idosos. No entanto, estas considerações raramente têm ido além das edificações, sendo que os espaços externos têm recebido muito pouca atenção. Para os autores ainda, muito da literatura técnica sobre o desenvolvimento de habitações para este grupo tem tratado a paisagem externa como um "cosmético" para as edificações, ao invés de tratá-la como uma parte do ambiente total da moradia. Este posicionamento, afirmam, tem como conseqüência a limitação dos horizontes dos residentes às paredes da edificação.

As discussões que serão apresentadas a seguir baseiam-se em resultados oriundos de uma dissertação de mestrado desenvolvida sobre este tema, e que teve como objeto de estudo a realidade vigente no município de Porto Alegre-RS (TOMASINI, 2002). Serão apresentados e discutidos, portanto, os principais resultados de dois estudos de campo que fizeram parte da pesquisa anteriormente citada. O primeiro destes estudos consiste de um levantamento preliminar onde foram analisados aspectos físicos dos espaços externos de uma amostra composta por 12 instituições distribuídas na zona urbana de Porto Alegre. O segundo refere-se a um estudo de casos comparativo envolvendo duas instituições de perfis semelhantes quanto a uma série de aspectos (público-alvo, serviços oferecidos aos residentes, instalações 
físicas no que diz respeito às edificações, etc.), porém com espaços abertos disponíveis bastante diferenciados entre si (uma instituição com grande disponibilidade de espaços abertos e outra com áreas externas bastante restritas).

\section{A Realidade de Porto Alegre}

A fim de verificar a realidade dos espaços abertos existentes junto às instituições que atendem a parcela de idosos de menor poder aquisitivo no município de Porto Alegre, foi desenvolvido um estudo envolvendo o levantamento de características físicas dos espaços de uma amostra de instituições.

Foram utilizados como critérios para a composição da amostra os seguintes fatores: o valor cobrado como mensalidade pelas instituições, o porte da instituição e a localização. Estes dados foram obtidos a partir do trabalho de Mello et al. (2000), o qual identificou um total de 101 instituições que trabalham com idosos em Porto Alegre e levantou diversas informações sobre as mesmas.

Estipulando-se um valor máximo de mensalidade de 3 salários míni$\operatorname{mos}^{5}$ e procurando-se compor uma amostra representativa para diferentes portes quanto ao número de leitos disponíveis ${ }^{6}$, chegou-se a uma amostra composta por 12 instituições: 5 de pequeno porte, 3 de médio porte, 2 de grande porte e 2 de porte especial. A fim de se detectar possíveis variações na disponibilidade de área dos espaços abertos das instituições em função de suas localizações, procurou-se ainda distribuir a amostra para diferentes regiões de Porto Alegre, como pode ser visualizado junto à Figura 1.

\footnotetext{
${ }^{5}$ Tendo em vista que todas as instituições para idosos de Porto Alegre cobram algum valor de mensalidade de seus residentes e que o objetivo da pesquisa era estudar as instituições que atendem a parcela mais carente dos idosos institucionalizados, estipulou-se um valor máximo de mensalidade equivalente a 3 salários mínimos (com base no valor do salário mínimo vigente em dezembro de 2000, equivalente a $\mathrm{R} \$ 150,00)$.

${ }^{6}$ A classificação das instituições quanto ao porte seguiu o modelo proposto pelo Conselho Regional de Enfermagem (2000), que classifica as instituições em: pequeno porte (até 20 leitos), médio porte (de 21 a 40 leitos), grande porte (de 41 a 60 leitos) e porte especial (acima de 60 leitos).
} 


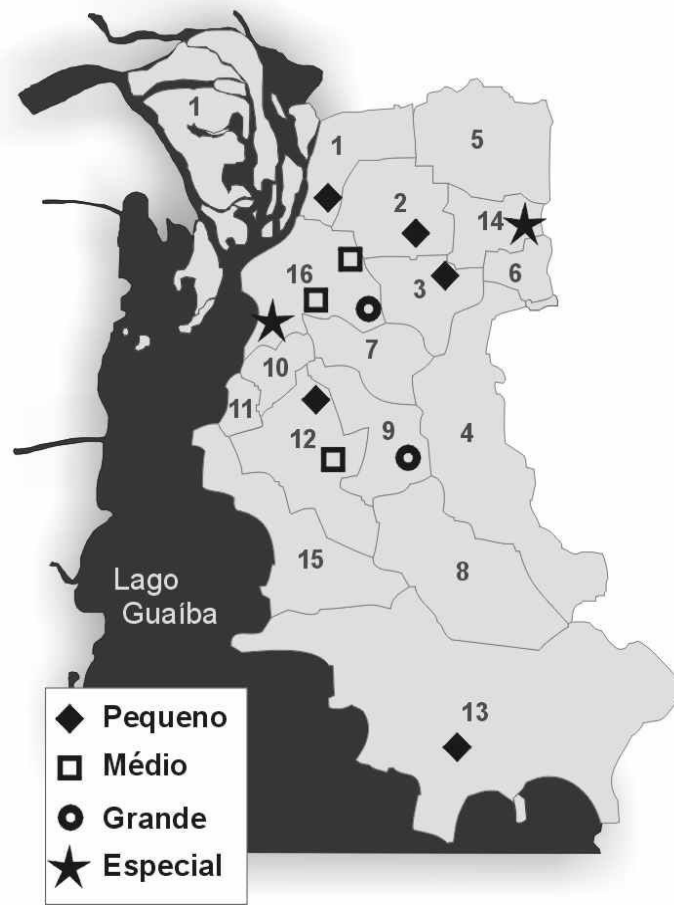

FIGURA 1: Distribuição da amostra para diferentes regiões de Porto Alegre *
*Regiões de Porto Alegre:

1-Humaitá/Navegantes/

Ilhas;

2-Noroeste;

3-Leste;

4-Lomba do Pinheiro;

5-Norte;

6-Nordeste;

7-Partenon;

8-Restinga;

9-Glória;

10-Cruzeiro;

11-Cristal;

12-Centro Sul;

13-Extremo Sul;

14-Eixo Baltazar;

15-Sul;

16-Centro.

Os levantamentos foram realizados através de visitas aos locais e consistiram de medições das áreas externas, da descrição e caracterização de seus elementos (acessos, caminhos, tipos de piso, equipamentos, vegetação, etc.), bem como do registro fotográfico das áreas. Tomando-se por base estes dados, foram elaboradas as plantas baixas de cada uma das áreas visitadas, as quais, juntamente com os registros fotográficos, foram utilizadas como suporte à análise dos dados.

Analisando-se as características físicas dos espaços abertos levantados, verificou-se a ocorrência de áreas extremamente restritas do ponto de vista do espaço físico disponível para os idosos, especialmente entre as instituições de pequeno porte, onde foram encontradas as situações mais críticas. As instituições para as quais verificou-se esta limitação apresentam perfil bastante semelhante: todas são edificações unifamiliares, adaptadas para o 
atual uso; trata-se de imóveis alugados que são administradas por proprietários particulares. O maior problema verificado nas instituições com este perfil, em relação à disponibilidade de áreas externas, foi a utilização compartilhada do pátio com o desenvolvimento de serviços, principalmente a secagem de roupas de cama. A demanda por espaços para este tipo de serviçoé bastante comum em instituições desta natureza, tornando indisponível para os idosos a maior parte dos espaços externos às edificações quando a área total dos mesmos é muito limitada. Em duas das instituições estudadas, o uso compartilhado do pátio com o desenvolvimento deste tipo de serviço indisponibiliza quase completamente os espaços externos para os idosos em dias de sol (Figuras 2 e 3 ).

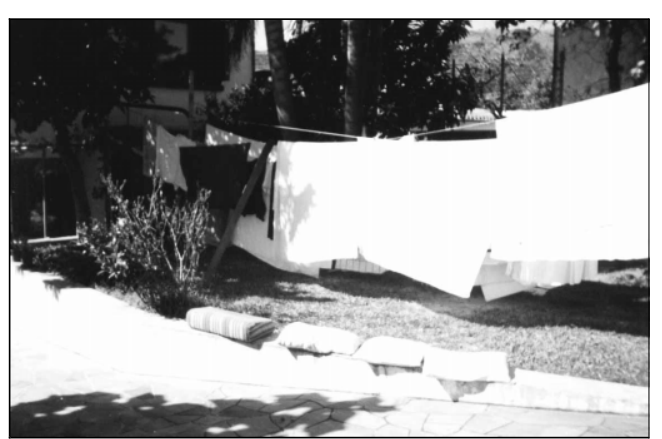

FIGURA 2: Instituição P4 - pátio utilizado para serviços

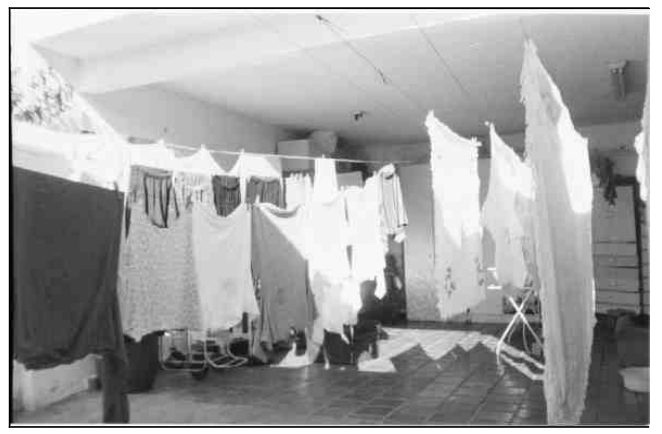

FIGURA 3: Instituição P5 - pátio utilizado para serviços

A constatação da ocorrência de situações mais críticas junto a instituições de pequeno porte, em relação à disponibilidade de áreas externas para os idosos, vem somar-se aos resultados da pesquisa realizada por Bastian (1979). Ainda no final da década de 70, esta pesquisadora procurou investigar possíveis relações entre a capacidade física de instituições para idosos (em número de leitos) e os recursos existentes para assistência aos seus residentes através do estudo de uma amostra de estabelecimentos localizados em Porto Alegre. Bastian verificou com este estudo uma relação direta entre número de leitos e recursos disponíveis, ou seja, as instituições com maior capacidade física eram aquelas que dispunham de recursos mais completos para seus residentes, incluindo condições superiores de instalações e equipamentos, planta física e programação. 
Confirmando o que se previa no início do desenvolvimento da pesquisa, embora algumas soluções positivas tenham sido encontradas em algumas instituições, nenhum dos espaços estudados parece ter sido executado a partir de um planejamento prévio, muito menos a partir de uma estudo específico para as necessidades dos idosos. Em função disso, diversos problemas puderam ser verificados quanto às questões funcionais e quanto ao aspecto visual dos espaços abertos existentes nas instituições. Desta forma, aspectos como a priorização de serviços em detrimento das funções de lazer, a falta de infra-estrutura de apoio ao lazer e a baixa qualidade estética das áreas externas, ${ }^{7}$ enquanto fatores que reduzem as possibilidades de utilização dos espaços abertos pelos idosos, foram identificados mesmo nas instituições que apresentaram grandes áreas externas.

Observou-se, por exemplo, que na maior parte das instituições que apresentaram amplas áreas externas não parece haver uma preocupação em disponibilizar espaços interessantes que estimulem a sua utilização pelos idosos. Pelo contrário, nestes locais, os espaços estão organizados e apoiados por infra-estrutura adequada às necessidades dos funcionários e dos visitan-

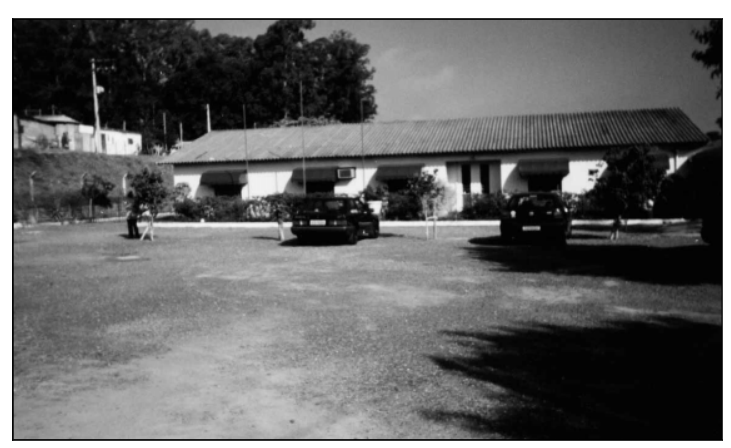

FIGURA 4: Instituição E2 - estacionamento situado na frente do lote tes e não dos idosos. Assim, por exemplo, verificam-se caminhos pavimentados e protegidos da chuva nas rotas de serviço e amplos estacionamentos localizados em posições nobres dos lotes, freqüientemente em frente aos mesmos (Figura 4). Por outro lado, pouca ou nenhuma infra-estrutura de apoio ao lazer é oferecida aos idosos, tornando as áreas externas pouco atrativas e muito pouco utilizadas pelos idosos.

Estas observações concordam com a experiência relatada por Sommer (1973) que, ao estudar uma enfermaria para senhoras idosas no Canadá,

\footnotetext{
${ }^{7}$ Cabe salientar que a baixa qualidade estética das áreas externas aqui mencionada refere-se à aridez visual dos espaços estudados e à falta de elementos visuais capazes de conferir interesse a estes locais. Esta afirmativa diz respeito somente à avaliação das características físicas dos espaços abertos realizada pelo pesquisador e não à avaliação da percepção dos usuários sobre a qualidade visual destes espaços.
} 
constatou que o ambiente da instituição era organizado para satisfazer as necessidades dos funcionários e familiares, enquanto as pacientes eram simplesmente "organizadas pelo ambiente". Avaliando as instalações da instituição, por exemplo, ele verificou que a sala de estar das idosas era utilizada como um corredor de serviços para os funcionários. Desta forma, a disposição das cadeiras das idosas era definida pelos funcionários, que as colocavam em fileiras junto às paredes a fim de facilitar a limpeza do local, a passagem de carrinhos de refeições e a observação das idosas. De acordo com este mesmo autor, o planejamento adequado é necessário principalmente em locais onde as pessoas são muito passivas ou dependentes. Estas pessoas dificilmente tomarão a iniciativa de arrumar ou intervir em seus ambientes a fim de ajustá-los às suas necessidades.

A maioria das instituições apresentou soluções que demonstram preocupação com questões de acessibilidade e segurança; no entanto, observouse que esta preocupação está concentrada sobre os aspectos físicos das edificações. Desta forma, embora se observem cuidados com os acessos aos espaços externos através da presença de rampas, corrimãos e pisos antiderrapantes, não foram verificados cuidados quanto à acessibilidade e à segurança especificamente ao longo dos espaços abertos. A presença de caminhos com adequada pavimentação que permita o deslocamento de cadeira de rodas e com a presença de corrimão para idosos que necessitam de apoio para caminhar não foram identificados em nenhum dos pátios estudados. Esta situação certamente inibe a utilização do pátio por idosos que apresentam maiores dificuldades de locomoção.

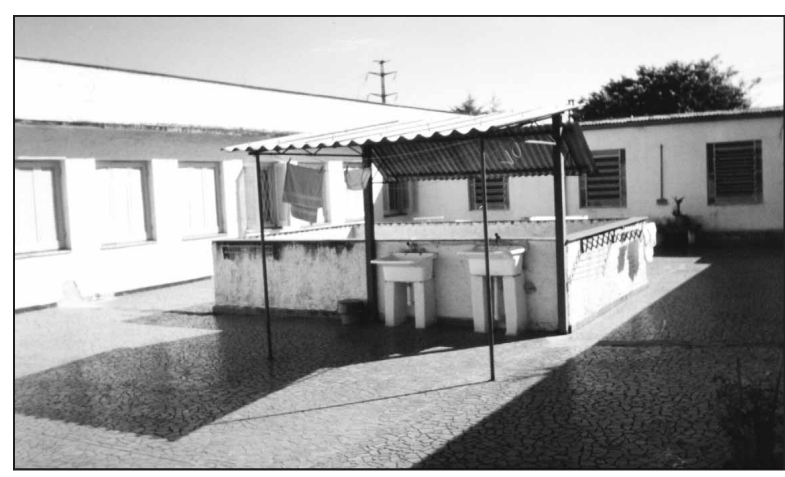

FIGURA 5: Instituição G1 - tanques de lavar roupa disponíveis para as senhoras

Apesar da baixa qualidade dos espaços abertos, observada de forma geral para olevantamento, algumas soluções interessantes puderam ser encontradas junto a algumas instituições. Em duas instituições, que trabalham exclusivamente com senhoras, são disponibilizados, junto 
aos espaços externos, tanques para as idosas que desejam lavar suas roupas. Embora ambas instituições disponham de serviços de lavanderia à disposição das senhoras, existe uma preocupação em proporcionar atividade e estimular a independência das idosas (Figura 5). Em outra instituição, verificou-se a pre-

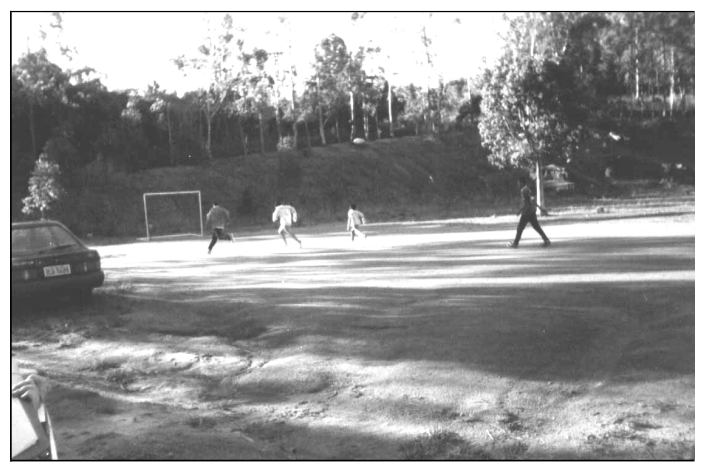

FIGURA 6: Instituição G2 - campo de futebol como atrativo para a comunidade local sença de um campo de futebol disponível para a comunidade local. O campo de futebol atrai crianças e adultos para dentro da instituição promovendo o contato dos idosos com outras gerações, o que certamente contribui para amenizar sentimentos de solidão e isolamento do mundo exterioràinstituição(Figura6).

A vegetação é um elemento presente em todos os locais visitados. A ausência de planejamento paisagístico das áreas, no entanto, torna a vegetação pouco atrativa visualmente na maioria dos casos e pouco funcional no sentido de configurar áreas de descanso e contemplação, bem como no sentido de melhorar as condições de conforto térmico das edificações. A possibilidade de os idosos cultivarem plantas nos espaços abertos foi observada em poucas instituições, sem, no entanto, contarem com locais específicos, de fácil acesso e adequados às limitações físicas dos idosos.

\section{O Pátio e os Idosos}

O segundo estudo de campo que fez parte da pesquisa consistiu de um estudo de casos envolvendo duas instituições selecionadas dentre aquelas visitadas durante a realização do levantamento preliminar anteriormente mencionado.

Este estudo teve por objetivo comparar as percepções e atitudes dos idosos em relação aos espaços abertos disponíveis nas instituições, sob diferentes condições de disponibilidade e qualidade das áreas externas. Desta forma, para participar deste estudo, foram selecionadas duas instituições semelhantes quanto a uma série de aspectos (público-alvo, serviços oferecidos 
aos residentes, instalações físicas no que diz respeito às edificações, etc.), porém, com espaços abertos disponíveis bastante diferenciados entre si. Uma das instituições, que será identificada aqui como Instituição A, apresentava grande disponibilidade de espaços abertos, sendo que estas áreas foram consideradas de qualidade superior por apresentarem maiores possibilidades de utilização pelos idosos. A outra instituição, que será identificada como Instituição B, por outro lado, apresentava áreas externas bastante restritas e de qualidade inferior, com poucas possibilidades de utilização.

Foram realizadas entrevistas com os idosos e com os demais personagens da instituição (administradores, funcionários e visitantes), sendo estes últimos agrupados em uma única categoria de entrevistados, denominada não-idosos para fins de análise dos dados. As entrevistas eram abertas e envolviam questões sobre a importância e utilização do pátio pelos idosos. As categorias de respostas encontradas para as entrevistas foram construídas a partir de palavras-chave extraídas da transcrição das respostas dos entrevistados. Somando-se as duas instituições, foram aplicadas 44 entrevistas ( 23 com idosos e 21 com os demais personagens da instituição). A fim de confirmar os dados fornecidos pelas entrevistas, foram realizadas ainda observações sobre a utilização do pátio pelos idosos durante as visitas às instituições.

Embora este estudo tenha gerado resultados de caráter mais exploratório do que conclusivo, devido ao pequeno universo de instituições pesquisadas e ao reduzido número de entrevistas aplicadas, estes resultados suscitam uma série de discussões bastante pertinentes, principalmente tendo-se em vista a escassez quase total de informações relacionadas a este tema junto à literatura científica nacional. Dentre os diversos resultados gerados por este trabalho, serão abordados a seguir apenas aqueles que estão mais relacionados diretamente com os objetivos deste artigo, que consiste justamente em discutir a importância da presença de espaços abertos junto a instituições para idosos.

Uma das questões avaliadas por meio das entrevistas foi o grau de importância atribuído ao pátio em relação à satisfação com a instituição como um todo. Para isso, após os entrevistados responderem se gostavam ou não de morar na instituição, era solicitado aos mesmos que justificassem suas respostas. O gráfico 1 mostra as frequiências percentuais de respostas para os fatores que influenciam a satisfação dos idosos com a instituição 
segundo os diferentes grupos de entrevistados (onde, IA - idosos da Instituição A; NIA - não-idosos da Instituição A; IB - idosos da Instituição B; NIB - não-idosos da Instituição B).

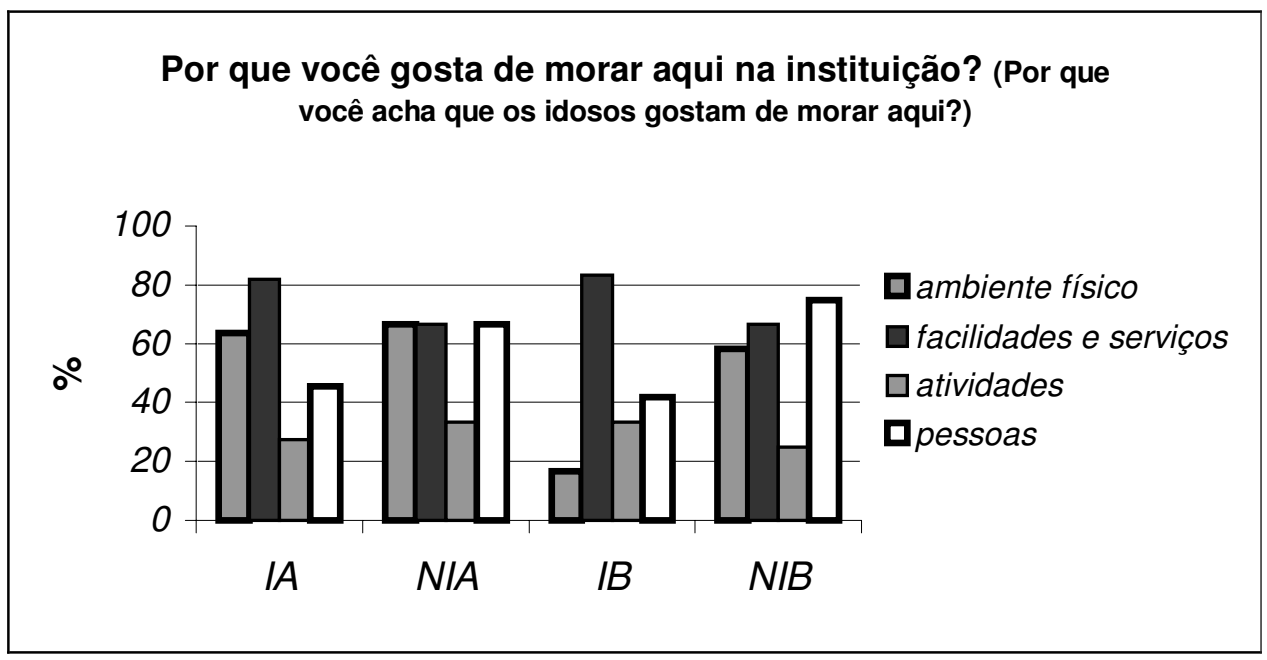

GRÁFICO 1: Freqüências para aspectos que influenciam a satisfação dos idosos em relação à instituição em função da instituição e do grupo de entrevistados

Observa-se, em geral, uma maior freqüência de respostas dos grupos de idosos para a categoria facilidades e serviços. Para os entrevistados dos grupos dos não-idosos, no entanto, a satisfação dos idosos com a instituição parece receber influência de um equilíbrio entre os aspectos facilidades $e$ serviços, pessoas e ambiente físico, sendo que uma menor influência parece ser exercida pelo aspecto atividades. Pode-se verificar ainda que a categoria ambiente físico é mais freqüente para os respondentes da Instituição A, especialmente entre o grupo dos idosos (IA). Isto significa que os respondentes da Instituição A tendem a relacionar mais a sua satisfação com a instituição com as instalações físicas disponíveis na mesma quando comparados aos respondentes da Instituição B. Esta observação foi particularmente importante para esta pesquisa, principalmente quando são analisados os conteúdos das entrevistas em sua íntegra, onde os respondentes da Instituição A predominantemente apontam as áreas externas da instituição e não as edificações como responsáveis pela satisfação dos idosos com o ambiente físico de moradia. 
A maior importância atribuída aos espaços abertos pelos respondentes da Instituição A em relação à satisfação com a instituição como um todo, certamente se explica pelo fato de estas áreas estarem muito mais presentes na vida dos residentes do que as áreas externas da Instituição B para seus residentes. Desta forma, quando questionados sobre os locais onde os idosos mais permanecem durante o dia, os respondentes da Instituição A apresentaram frequiências semelhantes de respostas para as categorias áreas externas e ambientes internos. Já para o respondentes da Instituição B, as freqüências para ambientes internos foram visivelmente superiores às freqüências de respostas para a categoria áreas externas (Gráfico 2).

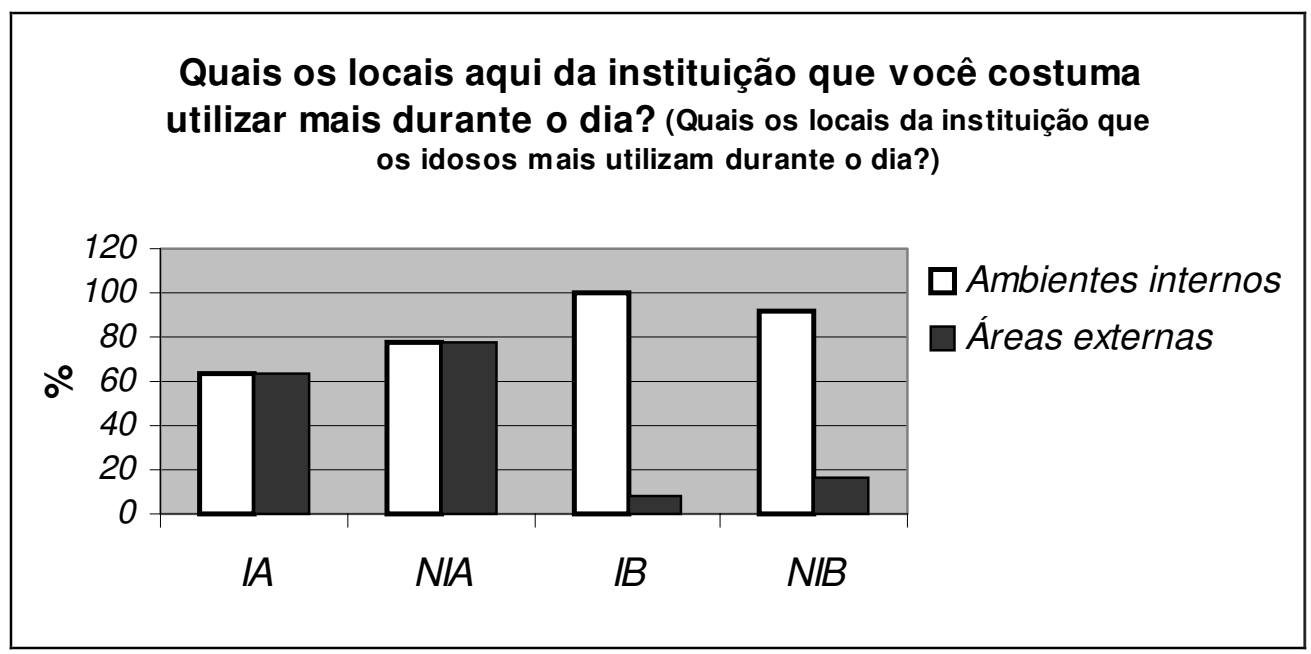

GRÁFICO 2: Freqüências para locais da instituição mais utilizados pelos idosos durante o dia em função da instituição e do grupo de entrevistados

Isto sugere um maior tempo de permanência dos idosos da Instituição A em áreas externas do que os idosos da Instituição $B$, o que é extremamente interessante tendo em vista os benefícios do contato com estes espaços, mencionados no início deste artigo. As observações realizadas à campo em ambas instituições confirmaram estas tendências. Certamente, a superioridade dos espaços abertos na Instituição A, tanto em termos de área disponível como em termos de qualidade desses espaços, exerce uma influência direta sobre os hábitos dos idosos. A abundante vegetação que confere ao pátio um aspecto de "sítio", a disponibilidade de recantos sombreados onde os idosos encontram privacidade e tranqüilidade, locais para a realização de caminhadas, e a presença de animais domésticos (gatos e galinhas), representam fon- 
tes de interesse que incentivam e estimulam a maior utilização do pátio pelos idosos. O pátio da Instituição B, por outro lado, não oferece condições para que os idosos permaneçam mais tempo "fora de casa". A topografia acidentada do terreno impede o acesso dos idosos à maior parte do pátio, não há bancos suficientes nem adequados para os idosos e não há a presença de recantos onde os residentes possam encontrar privacidade e sossego.

Outra questão investigada pela pesquisa foi o hábito dos idosos de visitarem outros espaços abertos fora da instituição, tais como parques e praças. Questionados a respeito da utilização desses espaços, apenas uma pequena fração dos idosos de ambas as instituições afirmou visitar locais desta natureza com freqüência, enquanto a grande maioria afirmou que o fazem apenas esporadicamente ou nunca o fazem (Gráfico 3).

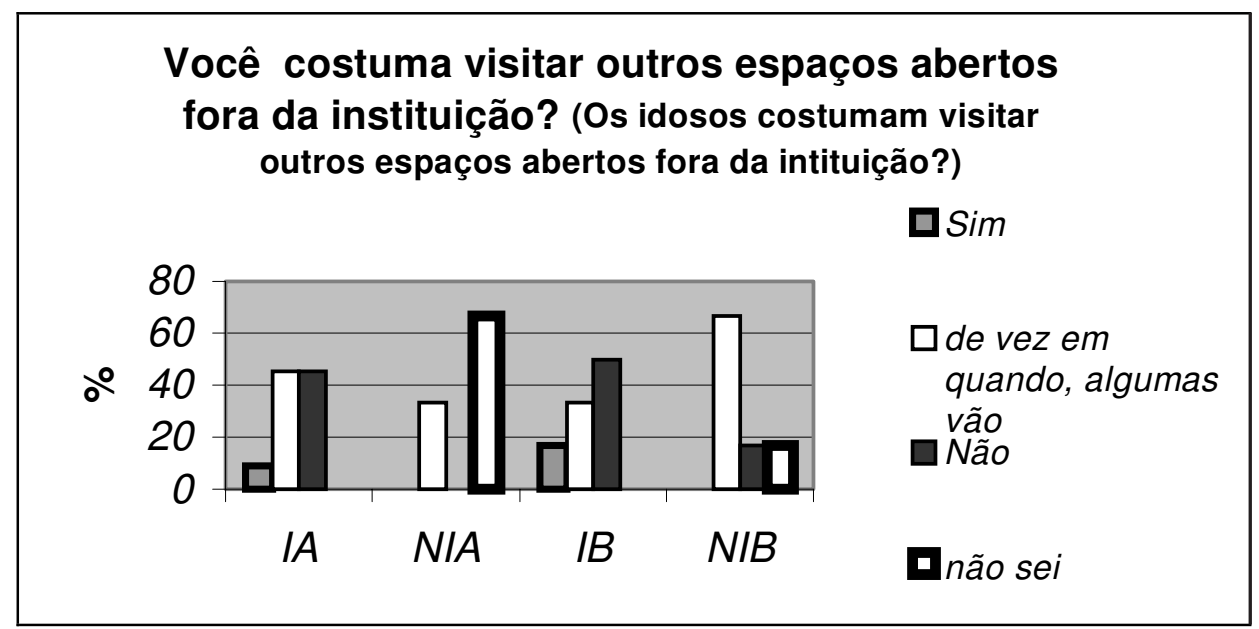

GRÁFICO 3: Freqüências para visitas a outros espaços abertos fora da instituição em função da instituição e do grupo de entrevistados

Observa-se ainda que para os não-idosos da Instituição B, a categoria mais freqüente foi de vez em quando, algumas vão, enquanto os respondentes do grupo dos não-idosos da Instituição A tiveram bastante dificuldade em responder esta questão. Esta diferença entre as respostas dos não idosos das duas instituições pode estar relacionada principalmente ao seguinte aspecto: os idosos da Instituição B provavelmente saem mais da instituição do que os idosos da Instituição A, uma vez que esta primeira instituição está localizada em área mais central e bastante próximo a uma praça, enquanto a segunda está localizada em bairro mais periférico e não possui 
nenhuma praça próxima. A dificuldade dos não-idosos da Instituição A em responder esta questão pode ser devida ao fato de que estes simplesmente não observam os idosos saindo da instituição.

De qualquer forma, de maneira geral, as respostas apontam para a falta de hábito dos idosos de visitarem outros espaços abertos fora da instituição. Este resultado reforça a importância da presença de espaços abertos junto às instalações físicas das instituições. De acordo com os relatos dos entrevistados, normalmente, os idosos que costumam visitar espaços abertos fora da instituição são aqueles que mantêm um vínculo maior com o mundo exterior. Alguns idosos mantêm uma vida relativamente dinâmica e independente dentro dos limites que a vida em uma instituição possibilita: vão ao mercado, pegam ônibus para ir ao centro ou visitar a família, vão à igreja, etc. Outros são mais dependentes da família para realizarem atividades fora da instituição. Para os idosos deste segundo grupo, as visitas a áreas verdes ou outros espaços abertos, normalmente, só se tornam possíveis quando familiares ou amigos vêm até a instituição buscá-los (geralmente, de carro). Embora seja extremamente importante e saudável para os idosos manter laços com o mundo exterior, este não é um benefício acessível a todos. De acordo com os relatos das entrevistas, é comum encontrar idosos que não possuem família ou amigos da mesma cidade, ou simplesmente não mantêm contato com a família, seja por motivos de abandono ou rompimento de relações. Estes idosos vivem praticamente somente aquilo que a vida institucional lhes proporciona. Passeios coletivos (como visita a parques, shopping centers, CTGs) foram relatados por entrevistados (idosos e não-idosos) de ambas instituições, porém, conforme relato dos administradores das instituições, estes passeios são raros e, normalmente, contam com a participação e o interesse de poucos idosos.

\section{Considerações Finais}

Os resultados da pesquisa apresentada neste artigo mostram, de maneira geral, condições insatisfatórias dos espaços abertos disponíveis junto às instituições que atendem a parcela mais carente dos idosos institucionalizados de Porto Alegre. A pesquisa também traz resultados que reforçam a discussão sobre a importância da presença de espaços desta natureza junto às instituições para idosos, ao observar uma influência positiva da qualidade desses espaços sobre a satisfação dos idosos em relação à 
instituição e sobre o tempo de permanência dos mesmos em áreas externas, além da pouca utilização de outros espaços abertos fora das instituições (como parques e praças) pelos idosos institucionalizados.

Embora se saiba das limitações econômicas enfrentadas principalmente pelas instituições que atendem os idosos de menor poder aquisitivo, os espaços abertos não podem ser negligenciados, dada a importância que os mesmos possuem sobre o bem estar dos idosos institucionalizados. Condições mais adequadas às necessidades dos idosos podem ser obtidas nestas áreas com soluções bastante simples e baratas através de um planejamento adequado dos espaços e através do incentivo das instituições à utilização dos mesmos pelos idosos.

\title{
OUTDOOR SPACES IN INSTITUITIONS FOR THE ELDERLY
}

\begin{abstract}
This article presents several aspects related to the importance of outdoor spaces in institutions for the elderly. It is based on the results of a master's degree research project on this topic, which was developed according to the analysis of the actual situation of institutions in the city of Porto Alegre-RS. Two field studies were the basic sources of data for this research: the first one analyzed the physical characteristics of outdoor spaces in a sample of 12 institutions; the second one was a comparative study including two institutions with different conditions regarding the availability and quality of outdoor spaces. The results of the first study showed an overall negative situation of availability and quality of outdoor spaces in the institutions. The spaces presented restricted availability and functionality and little aesthetic interest. The second study, on the other hand, showed the influence of the quality of outdoor spaces on the satisfaction of the elderly regarding the institution and their length of stay in the outdoor. This study also revealed that elderly people usually do not use the other open areas outside the institution, such as parks and squares, very frequently. This aspect highlights the importance of outdoor spaces in institutions for the elderly.

Keywords: Institutions for the Elderly. Open Spaces. Quality of Living.
\end{abstract}




\section{REFERÊNCIAS}

BASTIAN, E. M. Estudo sobre Acreditação de Internatos para Pessoas Idosas na Área Metropolitana de Porto Alegre-RS. 1979. Tese (Doutorado) - Faculdade de Saúde Pública, Universidade de São Paulo, 1979.

CANTUARIA, G. A. C. Microclimatic Impact of Vegetation on Building Surfaces. [1995?]. Dissertação (Mestrado) - Architetural Association Graduate School, London, 1995.

CONSEIL INTERNATIONAL DU BÂTIMENT. Working With the Performance Approach in Building. Rotterdam: CIB, [1982]. (Publication 64).

CONSELHO REGIONAL DE ENFERMAGEM. Proposta de Dimensionamento de Pessoal de Enfermagem em Instituições Gerontológicas e Geriátricas. Porto Alegre, 2000. Não publicado.

FEDRIZZI, B. Psicologia Ambiental: vegetação e diminuição do estresse. In: PETRY, C.; QUADROS, C. (Org.). SEMINÁRIO REGIONAL SOBRE PAISAGISMO URBANO, 1998, Passo Fundo. Anais... Passo Fundo: Ediupf, 1998. P. 31-35.

KÜLLER, M.; KÜLLER, R.; IMAMOGLU, E. O.; IMAMOGLU, V. Health and Outdoor Environment for the Elderly. In: PAMIR, H.; IMAMOGLU, V.; TEYMUR, N. (Ed.) Culture Space History. Proceedings of IAPS 11, July 812, 1990, v. 3. Ankara: METU Faculty of Architecture Press, 1990. P. 236245.

MELlO, A. L. S. F.; PADILHA, D. M. P.; ROSA, M. A. C. Casas Geriátricas de Porto Alegre: manual de orientação aos usuários. Porto Alegre: UFGRS, 2000.

SOMMER, R. Espaço Pessoal: as bases comportamentais de projetos e planejamentos. São Paulo: EPU, 1973.

STONEHAM, J.; THODAY, P. Landscape design for elderly and disabled people. Suffolk: Garden Art Press, 1994.

TOMASINI, S. L. V. Contribuições para o Planejamento de Espaços Abertos junto a Edificações de Instituições para Idosos. 2002. Dissertação (Mestrado) - Faculdade de Engenharia Civil, Universidade Federal do Rio Grande do Sul, 2002. 